\title{
Estimation of the consumer peak load for the Iraqi distribution system using intelligent methods
}

\author{
M. A. Al-Nama ${ }^{1}$, M. S. Al-Hafid ${ }^{2}$, A. S. Al-Fahadi ${ }^{2}$ \\ ${ }^{1}$ Department of Comp. Engg.Tech. Al Hadbaa Univ. College \\ ${ }^{2}$ Department of Electrical Engineering, Mosul University, Mosul- IRAQ
}

Email address:

mudhafaralnema@yahoo.com(M. A. Al-Nama),E__noor2000@yahoo.com(M. S. Al-Hafid), azhearlfahady@yahoo.com(A. S.Al-Fahadi)

\section{To cite this article:}

M. A. Al-Nama, M. S. Al-Hafid, A. S. Al-Fahadi. Estimation of the Consumer Peak Load for the Iraqi Distribution System Using Intelligent Methods. American Journal of Electrical Power and Energy Systems. Vol. 2, No. 5, 2013, pp. 111-115.

doi: $10.11648 /$ j.epes.20130205.11

\begin{abstract}
The drastic increase of residential load consumption in recent years result in over loading feeder lines and transformers for the Iraqi northern area distribution system especially in the city of Mosul. Solution for this problem require up to date research study consumers load to find the proper solution to stop excess overload in the transformers and the feeders. This paper include the regional survey for samples of consumers representing typical types of different standard of living and energy consumption by distributing questioners contain list of information such as load type in daily use. Also current readings are recorded for the individual consumer for the months of the year 2006. In addition to those readings, energy consumption is recorded once every two months. The registered readings are used in conjunction with the list of questioners to find a sample (for different loads) that coincide with the list of questioner for current and energy readings. Resulting in the feasibility of using the sample to know the peak value of current for any consumer not included in the list of questioner and for any new consumer, since it become possible to decide the size of the transformers and feeder lines, to overcome the problem of overloading in any part of the distribution system. The Artificial Neural Network (ANN) is used in this paper to find the above mentioned sample.
\end{abstract}

Keywords: Consumer Peak Load, ANN, Distribution System, Iraqi Distribution Network

\section{Introduction}

The estimation of the load is considered the foundation for the design and operation of the electrical power distribution system, where the load effects represent the most important variable in the electrical power system. As a result and the due to such effect the estimation of the load and the location and size of the substation for the region under study can be designed, also the detail specifications of the transmission lines and other components in the transmission and in the distribution of the electrical system can be specify $[1,2]$.

The engineers working in the office of electrical distribution in Nenava used to describe the types of consumers in to three categories according to the area size of their residential houses as small, medium and large areas. This method fails to satisfy the present situation of the residential consumer load. The Suggested category defines consumers according to their Load components and energy consumption as: low, medium and high consumption, therefore in this study the dependent was on the types of loads for subscribing the new categories.

Three transformers are chosen each represent a sample for each category, then the field survey is made to find the size of the present home consumption for the recent drastic change in consumption for calculating the diversity factor for different places in the distribution system.

The intelligent programming technique (ANN) is used in this research to find the relationships (according to the questioner information and recorded data) between the home load components and the peak current value. The ANN is highly flexible with special characteristics where accurate results are obtained in coincident with the expected load changes in future for the purpose of this work.

\section{The Artificial Neural Network}

The theory of the ANN is well known, which is used in solving problems of different specializations the ANN is trained to find complex functions in different applications 
including distinguishing samples, speech category, the control system and supervision. Also it is possible to train the ANN these days for solving problems that can not be solved in the classical programming methods $[3,4]$.

From the middle of the eightieth decade of the previous century, most of efforts were used in analyzing power system away from the classic mathematical simulation methods that include operational researcher, control theory and numerical method in the direction of technology of less complication than the (artificial intelligence AI).

The fundamental technology for the artificial intelligence used nowadays in the electrical power system applications is the one that accept the benefits of logic and the knowledge in simulation of the intelligent system or the fuzzy system or the artificial nerve network and recently in the developing mathematics [5].

\subsection{The Use of the ANN in Analysis}

The ANN is used in this paper in two basic steps they are:

1-. Categorizing the consumers according to the three suggested samples as mentioned in the previous paragraph.

2-. Finding the peak load current for every consumer.

\subsection{The Number of Sample in This Study}

Three different districts are chosen in the city of Mosul for this study.

1-. Region one: The first district representing low consumption consumers supplied by a $250 \mathrm{kVA}$ transformer with 11 consumers to the right of the transformer and 16 to the left, total of these consumer samples for this district were 27.

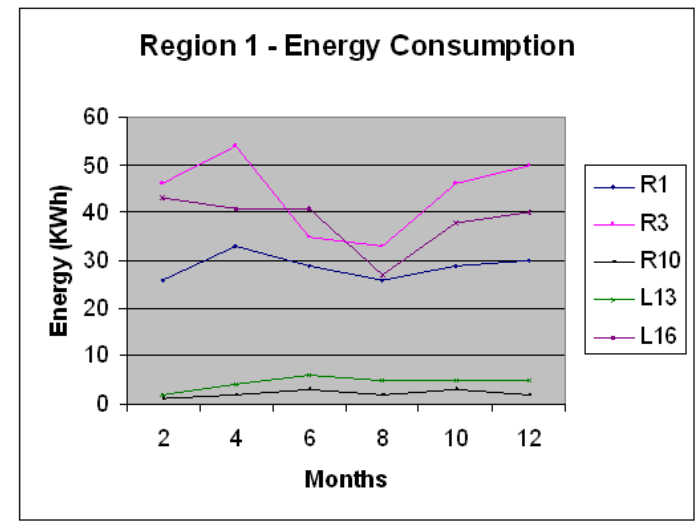

Figure 1. Average energy consumed - Region 1.

Figure 1 Shows samples of the average energy consumed by costumers in this region. Figure 2 shows samples of peak monthly current drawn by the consumers in this region.

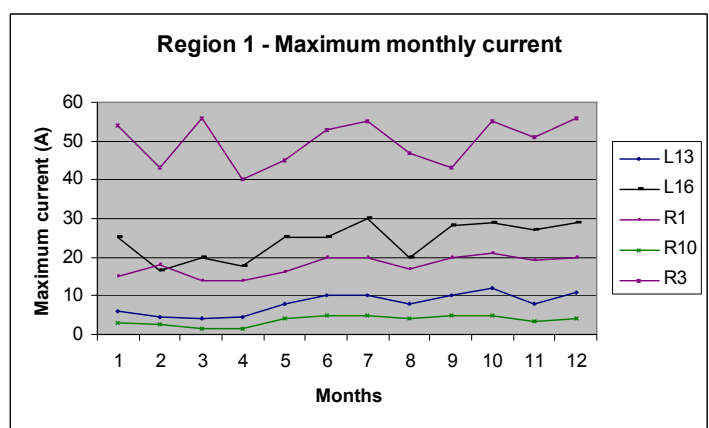

Figure 2. Maximum monthly current-Region 1.

1-. Region two: The second district represents the medium consumption supplied via a $250 \mathrm{kVA}$ transformer where 20 consumers are on the right side of the transformer and 19 to the left with a total of 39 samples.

Figure 3 Shows samples of the average energy consumed by costumers in this region. Figure 4 shows samples of peak monthly current drawn by the consumers in this region.

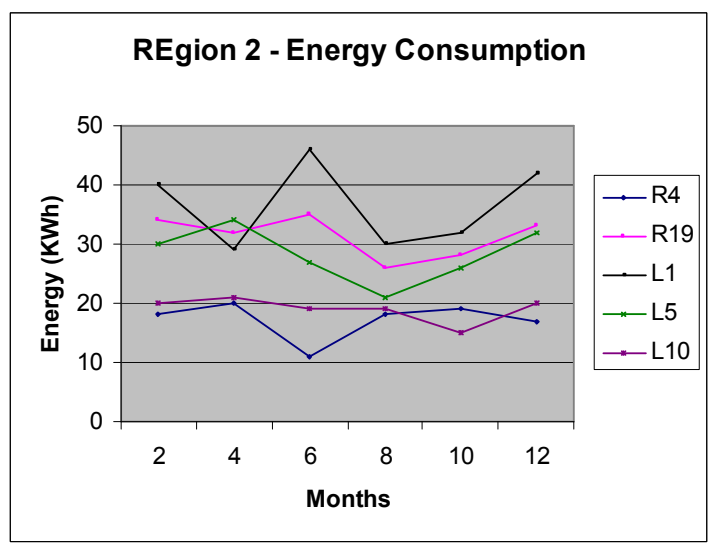

Figure 3. Average energy consumed - Region 2.

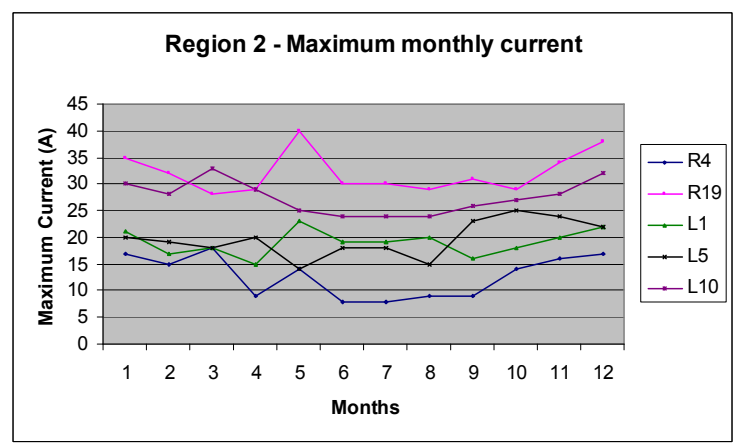

Figure 4. Maximum monthly current - Region 2.

1-. Region three: The third district represent the high consumption consumers supplied via a $400 \mathrm{kVA}$ transformer, with 15 consumer to the left of the transformer and 18 to the right the total were 33 samples. 


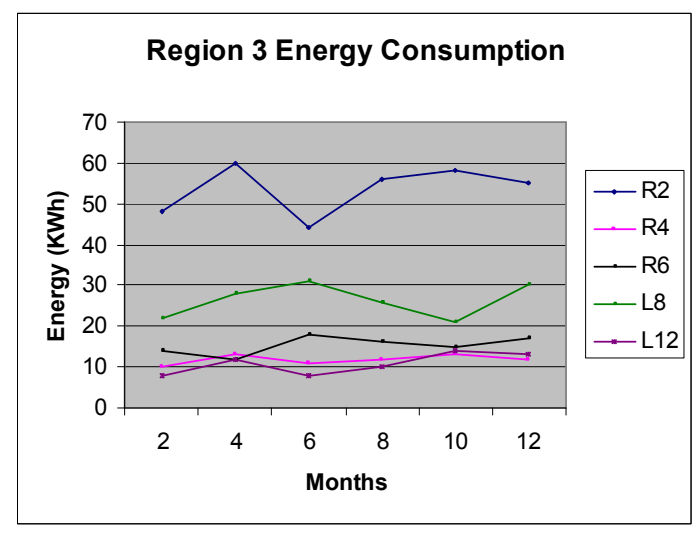

Figure 5. Average energy consumed - Region 3.

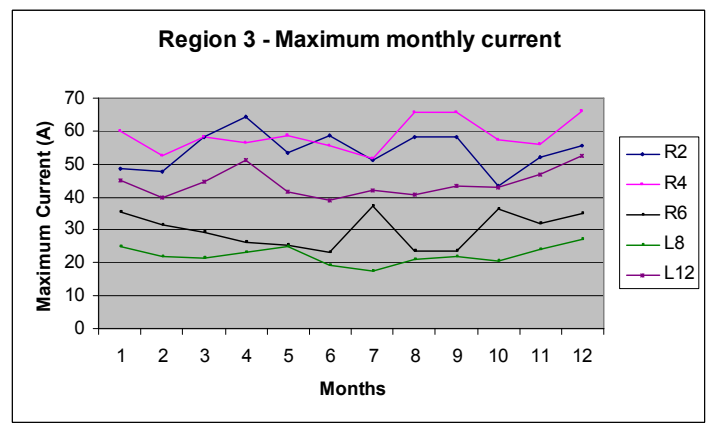

Figure 6. Maximum monthly current-Region 3.

The above samples represent the three district samples under study, their total number were 99 samples containing the recorded given information's enabling us using them for training or testing the two suggested ANN.

\subsection{The Consumers Categories}

The three distinguished categories are of great importance especially in finding the peak current of the consumers outside the sample study, also for the new added consumers.

The seven influencing factors values (the input variables) where the last two variable are deleted for the new consumers and for those outside the sample study, they are the average daily consumption of power and the peak current drawn by each consumer.

The ANN is used with two layers for the consumer's categories as discussed before. The output values represent the second and third consumer categories (medium and high consumption). Seven variables are used representing the input to the ANN they are:

1-. The type of the consumer subscription in the supply (single or three phases).

2-. The area of the consumer home.

3-. The number of persons in the home.

4-. The average peak of daily consumption of energy.

5-. The peak drawn current.

6-. Number of air conditioning equipments (window or split types).

7-. Number of heating equipments, (water heaters, stoves, air heaters).
The last two items representing the highest energy consumption factors. A sample consumers questioner information and recorded data are given in appendix 1 .

Figure 7 below is the block diagram for the ANN used in categorizing the consumers, in which the network comprise of two layers, the first is for 30 cells with seven variables for the input values while the second layer the output layer is composed of one cell (according to the number of variables to be found).

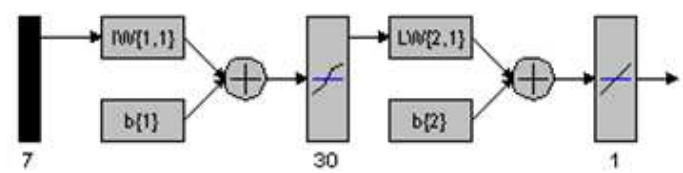

Figure 7. The block diagram showing the ANN used for categorizing the consumers.

\subsection{The Use of the ANN for Finding the Peak Current Drawn by the Consumer}

The different load items of the consumer (the questionnaire items) have a great effect on the peak load for every consumer. These include the air heating equipments, water heaters, cooling equipments such as fanes air coolers, air conditioners and others similar equipments also lighting equipments such as the lamps, the fluorescents and others, in addition to the kitchen equipments such as the refrigerator, the ice maker or freezer and washing machine and others. Also include the recording, radio, television and other electronic equipments such as computers with their accessories and other different loads such as water pumps.

The difference in weather condition effect very much on the type of the equipments used, it is clear that the heating and cooling equipments can not be used at the same time, also the buying ability of equipment is do not the same between the consumers with difference categories.

For example the buying ability for the first group (with low consumption) from cooling equipments do not be more than fanes and air coolers only, while the second and third group they are able to have air conditioning units or split units in addition to the fanes and air coolers or the kitchen equipments and others.

The ANN is used to find the relationship between the peak current drawn by the consumer with the different load consuming equipment (as in the survey questionnaire). The different factors for the load equipments that effect on the value of the peak current drawn are as follows:

1-. The size of the residential area the consumer living in.

2-. The number of spaces (bedroom, receptions, living kitchen rooms and others) used.

3-. Number of residents in the house.

4-. The audio video equipments (Television, recorder, radio, computer, ... etc.) used.

5-. The kitchen equipments (The multipurpose machine grinder, mixer, exhaust fan ... etc.).

6-. Food saving equipments (Refrigerator, freezer, water 
cooler ... etc.).

7-. Air conditioning equipments (window type or split type).

8-. Air cooler.

9-. Fan (Ceiling, vertical stand or table type).

10-. Washing machine (clothes, utensils).

11-. Water pump.

12-. Fluorescent lamp.

13-. Incandescent type lamp.

14-. Heating equipments (stove, heater, water heater ... etc.).

15-. The type of power supply (Single or three phases).

The ANN used to find the peak current drawn by the consumer is compose of two layers, the first layer contain 30 cells representing 15 input variable, which are taken from the survey sheet explained before for finding the peak current drawn by the consumer.

The following figure No. 8 is the block diagram for the ANN used. It is possible by using the ANN to find the peak load for any consumer, after gaining the special data for that customer according to the questionnaire sheet explained before. After getting the peak load of the consumers supplied to from a certain transformer then one has to make sure that the transformer and feeder are not overloaded and other distribution system are not extra overloaded too.

It is possible to find the transformer load depending on the diversity factor obtained by this study when adding a new customer then the decision is made for adding or rejecting such additional load.

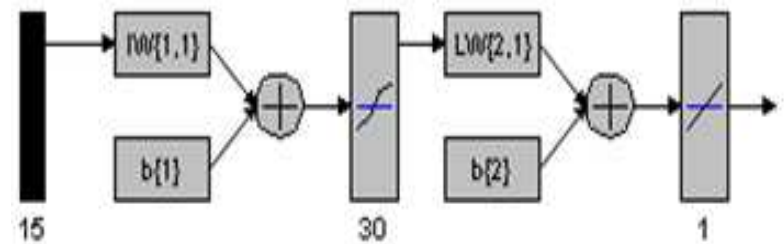

Figure 8. The block diagram for the ANN for finding the peak current.

\subsection{The ANN Training}

The gained information are divided into two parts where the first part is used for training the ANN while the second part is used for testing the ANN. The registered in formations contain the study samples (99 samples enabling us using them for the two suggested ANN in the research.

\subsection{Results of Testing the ANN}

The two suggested ANN presenting the following results:

1-. The ANN for categorizing consumers.

The ANN designed for this purpose after testing it in the training information's $100 \%$ accuracy and when tested by the information outside the training group it gave $100 \%$ accuracy too.

2-. The ANN for finding the peak consumers current.

The ANN designed for this purpose when tested by the training in formations presented $100 \%$ accuracy also when tested with information's outside the training group it gave $95-100 \%$ accuracy results. Such accuracy representing dependable values when designing new distribution networks or for correcting surplus sage of overloading on the exciting network.

\section{Results and Discussions}

The former classical method used by the administration of the electrical distribution in Neneva for the many previous decades to overcome and contain the quick variations in domestic load values, causes in the recent years surplus sage overloading in many places in the distribution system.

In the present research reliance was depending on new categories for consumer load components. A table of questioner is prepared to know singular load items of the consumers. A field study is made for one complete year of 2006 (In searching for load variations according to the weather condition) the load current values are recorded for the study samples with the energy consumption for the same period of study.

The ANN technology is used for simulating the relations between the consumer load components and the consumer peak current. The results obtained show the possibility of dependence on this technology for finding the peak load of the new consumer or for consumers outside the study samples.

\section{Appendix 1 Samples of Data}

\begin{tabular}{|c|c|c|c|c|c|c|c|c|c|c|c|c|c|c|c|c|c|c|}
\hline No. & 1 & 2 & 3 & 4 & 5 & 6 & 7 & 8 & 9 & 10 & 11 & 12 & 13 & 14 & 15 & 16 & 17 & 18 \\
\hline \multicolumn{19}{|c|}{ Region 1} \\
\hline R1 & 150 & 4 & 6 & 2 & 0 & 2 & 0 & 2 & 2 & 1 & 0 & 4 & 2 & 2 & 1 & 33 & 21 & A \\
\hline R3 & 250 & 7 & 17 & 2 & 0 & 2 & 0 & 2 & 4 & 2 & 2 & 9 & 2 & 2 & 1 & 54 & 56 & B \\
\hline $\mathrm{R} 10$ & 200 & 5 & 1 & 1 & 0 & 1 & 0 & 1 & 2 & 0 & 1 & 3 & 2 & 0 & 1 & 3 & 5 & A \\
\hline L13 & 85 & 4 & 4 & 2 & 0 & 1 & 0 & 1 & 2 & 1 & 1 & 4 & 1 & 0 & 1 & 6 & 12 & A \\
\hline L16 & 110 & 6 & 20 & 4 & 0 & 4 & 0 & 2 & 4 & 1 & 0 & 9 & 2 & 0 & 1 & 41 & 30 & B \\
\hline \multicolumn{19}{|c|}{ Region 2} \\
\hline R4 & 56 & 5 & 2 & 2 & 0 & 1 & 0 & 1 & 2 & 1 & 1 & 8 & 2 & 0 & 1 & 20 & 18 & A \\
\hline R19 & 110 & 7 & 11 & 2 & 3 & 2 & 1 & 2 & 5 & 1 & 1 & 8 & 4 & 2 & 1 & 35 & 40 & B \\
\hline L1 & 200 & 5 & 5 & 1 & 0 & 1 & 0 & 1 & 1 & 1 & 0 & 5 & 1 & 1 & 1 & 46 & 23 & B \\
\hline L5 & 200 & 5 & 9 & 2 & 0 & 1 & 0 & 1 & 1 & 1 & 1 & 6 & 1 & 1 & 1 & 34 & 25 & B \\
\hline L10 & 150 & 7 & 7 & 3 & 0 & 1 & 0 & 1 & 3 & 1 & 1 & 3 & 2 & 5 & 1 & 21 & 33 & B \\
\hline \multicolumn{19}{|c|}{ Region 3} \\
\hline
\end{tabular}




\begin{tabular}{|c|c|c|c|c|c|c|c|c|c|c|c|c|c|c|c|c|c|c|}
\hline No. & 1 & 2 & 3 & 4 & 5 & 6 & 7 & 8 & 9 & 10 & 11 & 12 & 13 & 14 & 15 & 16 & 17 & 18 \\
\hline R2 & 800 & 8 & 7 & 6 & 5 & 4 & 4 & 3 & 7 & 3 & 0 & 20 & 25 & 3 & 3 & 60 & 58 & $\mathrm{C}$ \\
\hline R4 & 400 & 8 & 11 & 6 & 6 & 3 & 5 & 1 & 10 & 2 & 1 & 12 & 25 & 2 & 3 & 13 & 66 & $\mathrm{C}$ \\
\hline R6 & 600 & 6 & 7 & 5 & 6 & 2 & 5 & 3 & 11 & 1 & 0 & 15 & 7 & 10 & 3 & 18 & 37 & $\mathrm{C}$ \\
\hline L8 & 400 & 6 & 4 & 4 & 2 & 1 & 3 & 1 & 6 & 1 & 0 & 8 & 12 & 0 & 3 & 31 & 21 & B \\
\hline L12 & 200 & 6 & 4 & 1 & 5 & 1 & 0 & 1 & 6 & 1 & 0 & 12 & 14 & 0 & 3 & 14 & 22 & B \\
\hline
\end{tabular}

R:Right L:Left No. means;

1:Area 2:No. of spaces $\quad 3:$ No. of resident $\quad 4$ :Aodio \&Video devices $\quad$ 5:Kitchen equipment $\quad$ 6:Food saving Eq.

7:Airconditioning eq. $\quad$ 8:Air coolers $\quad$ 9: Fans 10:Washing machines $\quad$ 11:Water Pumps 12:Fluoresent lamp

13:Incandescent type lamp 14:Heating eq. $\quad 15:$ Type of supply $\quad 16$ :Maximum average daily energy

17: Maximum monthly current

18:Consumer type

\section{Thanks and Appreciations}

The researchers express their deep gratitude and thanks to the administration and the engineers of the General Management for North Region Electrical Distribution for their valuable help and cooperation throughout this work and fruitful discussion and suggestions made among the different study stages.

\section{References}

[1] J. Nazarko, R. P. Broadwater \& N. I. Tawalbeh "Identification of statistical properties of diversity and conversion factors from load research data" Electro technical Conference, 1998. MELECON 98., 9th Mediterranean Volume 1, Issue , 18-20 May 1998, vol.1, PP 217 - 220.

[2] A. Sargent, R. P. Broadwater, J.C. Thompson \& J. Nazarko " Estimation of diversity and KWHR-to-peak-KW factors from load research data" IEEE Transactions on Power Systems, Volume 9, Issue 3, Aug 1994 PP 1450 - 1456.

[3] J. Hertz, A. Krough \& R. Palmer, "Introduction to the Theory of Neural Computation.” Addison - Wesley, 1991.

[4] P.D. Wassermann, " Neural Computing: Theory and Practice." New York, Van Nostrand Reinhold, 1989.

[5] Warwick, A. Ekwue \& R. Aggarwal "Artificial intelligence techniques in power systems" IEE Power Engineering Series 22, London, 19971 